\title{
La construcción de la relación entre el mundo simbólico y "lo ambiental" en las letras del repertorio musical huilense
}

\section{The construction of the relationship between the symbolic world and "the environment" in the lyrics of the Huilense musical repertoire}

\begin{abstract}
A construção da relação entre o mundo simbólico e "o ambiental" nas letras do repertório musical huilense
\end{abstract}

Leonardo Ruiz Méndez

Doctor en Educación y Cultura Ambiental

Universidad Surcolombiana leonardo1@usco.edu.co

\section{Resumen}

Este escrito pretende explicar la manera como en las letras de algunas canciones folclóricas huilenses, se expone "lo ambiental", es decir, las tensiones entre cultura-naturaleza (Ángel-Maya, 2013) que han construido la relación entre mundo simbólico y ecosistemas.

Palabras clave: Música del Huila, lo ambiental, cultura, naturaleza, mundo simbólico, ecosistemas.

\begin{abstract}
This writing aims to explain how, the lyrics of some popular folk songs from Huila, the environment issue has been related. That is, the tensions between culture-nature (Ángel-Maya, 2013) that have explored the relationship between the symbolic world and the ecosystems.

Keywords: Huila music, environment, culture, nature, symbolic world, ecosystems.
\end{abstract}




\section{Resumo}

Esta escrita pretende explicar como na letra de algumas canções folclóricas huilenses, "o ambiental" está exposto, ou seja, as tensões entre a culturanatureza (Angel-Maya, 2013) que construíram a relação entre o mundo simbólico e os ecossistemas.

Palavras-chave: Música Huila, meio ambiente, cultura, natureza, mundo simbólico, ecossistemas.

\section{Introducción}

La definición de mundo simbólico que intentamos aplicar nos la ofrece el pensador ambiental Augusto Ángel Maya (2013):

es el extenso mapa dibujado por una cultura para orientar los caminos individuales. Sin esta orientación de la geografía simbólica, el individuo no tendría posibilidad de acceso a las condiciones de vida más elementales ni podría recorrer los complejos y muchas veces peligrosos caminos de la experiencia cultural. (pág. 109)

La cultura se puede comprender como la vivencia del símbolo, palabra que proviene del griego simbalein que etimológicamente significa lanzar o arrojar juntos un objeto partido del cual dos personas se quedan cada una con una mitad. Esas dos partes, vueltas a reunir, dan fe de que ahí había un compromiso, un testimonio en común. En consecuencia, es a partir del lenguaje simbólico que se tienden las redes que van a permitir articular la realidad como lugar donde se construyen o denota un universo simbólico (Otero, 2018).

La posibilidad de compartir símbolos y, por tanto, de construir cultura, está en relación con lo manifestado por Coccia (2011) cuando habla del "comercio de lo sensible", aludiendo que es

la capacidad de producir imágenes de cosas: ni praxis ni poiesis, sino la esfera intermediaria de comercio y producción de lo sensible. No se trata apenas de la facultad de encarnar las formas en objetos, sino de la capacidad de hacerlas vivir por un instante fuera de las cosas y fuera de los sujetos. (pág. 66)

Imágenes y símbolos coexisten simultáneamente: son "naturaleza transformada" (Ángel-Maya, 2013). De esta manera, se comprende la definición de cultura como "el conjunto de la formación social que incluye las herramientas físicas (técnica), las formas de la organización social y las 
manifestaciones simbólicas"

(Ángel-Maya, 2013, pág. 80).

Compositores, intérpretes y público están continuamente desplegando su vida sensible, es decir, "el modo en que nos damos al mundo, la forma en la que somos en el mundo (para nosotros mismos y para los demás) y, a la vez, el medio en el que el mundo se hace cognoscible, factible $y$ vivible para nosotros" (Coccia, 2011, pág. 10). Así construimos el mundo-de-la-vida-cotidiana (Noguera, 2004), o sea, el cuerpo.

La relación continua de imágenes y símbolos está en relación con el sentir, y este vínculo es la forma como se expone el existir.

Desde la razón, se ha creído que somos en exclusividad pensamiento, no en vano Descartes pronunció su famosa frase "pienso, luego existo". La razón imperativa ha desplegado y decido la relación culturanaturaleza con las consecuencias manifiestas de esta crisis civilizatoria reinante.

"El comercio de lo sensible" (Coccia) que realizamos a través de imágenes y símbolos ha impactado en la relación culturanaturaleza. Por esto, la intención de encontrar en las letras de las canciones de música folclórica huilense el discurso que evidencia esta relación-tensión, es decir, el mundo simbólico que la constituye.

El estudio halló 4 grupos de canciones a saber: aquellas que describen la naturaleza; las que cantan a la relación entre mujer y naturaleza; las que exponen la correspondencia entre fiestas $y$ naturaleza; las que evidencian las tensiones con la economía. A continuación, se presentan cada uno de estos grupos de canciones.

\section{Descripción de la naturaleza}

En las letras de las canciones folclóricas huilenses se expone explícitamente el reconocimiento a la majestuosidad de la naturaleza. Río que nutre la vida, maizal y platanal que alimentan, labranza del sentir en comunión:

En mi tierra para bien, cruza un rio sin igual, que da la vida entera al labrador, a su maizal, al platanal. Es el Huila mi sentir, doy mi vida por volver y a mi tierra querida cantarle con placer. (“Alma del Huila" - Luis Alberto Osorio)

La sintonía con el lugar se canta así:

Azules se miran los cerros en la lejanía, paisajes de ardientes llanuras con sus arrozales de verde color. En noches, noches de verano brillan los luceros con más esplendor, la brisa que viene del río me dice "Hasta 
luego”, yo le digo “Adiós”. (“Al sur" - Jorge Villamil Cordovez)

Religión-naturaleza, donde la figura de un Padre Creador define el lugar por donde corre el río. Agua para la vida: "Creó el Río Magdalena para que todo Colombia pudiera beber el agua de esta tierra que es la gloria" ("Mi Huila" - Héctor Álvarez).

La mitología huilense también se encuentra relatada en forma de canto. Las metáforas de la cuidadora del monte y el guardián del río se enuncian así: "Solían ver ilusiones como la del Mohán en el río... la Madremonte corría detrás del niño inocente..." ("Mitología Huilense" - Luis Carlos "Pipa" Prada).

También en la naturaleza nos encontramos con la tristeza. Una congoja que habla de las duras experiencias de los seres humanos en medio de la soledad y la guerra: "Y todos vamos llorando o cantando por la vida, somos como los guaduales a la vera del camino" ("Los Guaduales" - Jorge Villamil Cordovez).

\section{Mujer y naturaleza}

La naturaleza presta un servicio metafórico para describir las bondades de la mujer y del amor. Cuando el amor surge, el rio, las plantas con sus flores, el fuego y los animales son testigos:
Espejos tembladores de aguas fugitivas, van retratando amores y bellos recuerdos que deja la vida. Se trenzan en coronas de blancos azahares, de rosadas diademas cuando llevan flores de la siempreviva. ("Espumas" - Jorge Villamil Cordovez)

Yo me bailo mi guabina con mi morena, con mi morena, al arrullo de las aguas del Magdalena, del Magdalena. ("Guabina Huilense" -Carlos Enrique Cortés).

Te acuerdas de la fuente cristalina, los algarrobos que perfumaban con sus flores que al borde son rojizos y de los nidos que allí colgaban. ("Flor del campo" - Luis Alberto Osorio)

La mujer que en la cintura es una danza morena que huele a ron y a locura, que huele a ron y a locura a orillas del Magdalena. ("Caminando por el Huila" José Ignacio Olave)

Muchachita campesina, te conocí en la montaña, entre flores y palmeras, cual feliz mariposa cuando llega primavera. ("Muchachita campesina" - Gerardo Betancourt y Ruth Rojas de Polanco)

La noche nos ocultó, la luna nos embrujaba, el fuego que allí surgió, de humedad nos inundaba, la sombra se 
perfumó con suave olor a madera, la ropa al suelo cayó de nuestros cuerpos de arena. (“Culpa divina” -Jaime Ricardo Guío Ordóñez)

Los colores del amor alegres se dibujaban, mil mariposas sentí dentro dentro mi ellas volaban, le dije lo que sentía, dibujado en mi mirada, pero ella se fue de mi como el río con sus aguas. ("A orillas del Magdalena” - Ricardo Castro Silva)

En la constitución de la familia:

Ella me lava la ropa, me remienda las camisas, me surce los calzoncillos y recoge las chamizas, le da comer al niño, le echa maíz a las gallinas. ("Camino real" - José Ignacio "Papi" Tovar)

Al desamor también se canta:

Pero despierto y vuelvo a recordar que el mundo sigue loco en su girar. Se fue mi amor, todo acabó, solo ha quedado allí el caracolí. ("Caracolí” -Jorge Villamil Cordovez)

Soy el verso vivo de la de mi gente, en mis cuerdas muere la tristeza, llevo en la madera el olor de la nostalgia de amores habidos en bohemia serenata. ("Mensajero de paz" - Juan Pablo Rodríguez Mendoza)
Y no podré llorar, tampoco he de reír; mejor guardo silencio porque ha llegado el fin. Lo nuestro terminó cuando acabó el amor, como se va la tarde al ir muriendo el sol. Siempre recordaré aquellos ojos verdes, que guardan el color que los trigales tienen. A veces yo quisiera reír a carcajadas, como en la mascarada, porque eso es nuestro amor. ("La Llamarada" Jorge Villamil Cordovez)

Porque me llevarás unido a tu recuerdo, como la luz del sol, como el agua y el viento, porque me llevarás unido a tu recuerdo. ("Me llevarás en ti" Jorge Villamil Cordovez)

\section{La fiesta y la naturaleza}

Las fiestas del San Juan (24 de junio) y del San Pedro (29 de junio) también forjan la relación simbólica de la tensión culturanaturaleza, exponiendo así "lo ambiental". Se hace mención del licor, la parranda y la comida:

Sírvame un trago de a cinco, sírvame otro de a cincuenta, sirva y sirva sin descanso hasta que pierda la cuenta y vamos a bailar al son de este joropo la vida hay que gozar. ("Sanjuanero huilense" - Anselmo Durán Plazas)

La chicha, el guarapo y el viudo de pescao, mantienen alegre al hombre enamorao. ("Caña No. 1" - Cantalicio Rojas) 
Qué viva el amor, qué viva la vida. Viva la parranda, viva mi novia y que viva el Huila...la vida es muy corta y hay que gozarla bien sabrosito, así que mi amor, un besito más y otro aguardientico, vamos a bailar es tiempo de enamorar, despegadito mi vida porque mi suegra se va a enterar. ("Rumba Opita” - Luis Alfonso Castellanos)

Hay una fiesta muy popular que los opitas saben gozar, es el San Pedro tradicional con su bambuco y su tamborear. Y cuando llega el San Juan principia la comelona, se prepara la lechona y se cocina el tamal. Y los envueltos e insulsos recobran actualidad $y$ las arepas de mote también salen a bailar. ("Fiestas opitas" Ramiro Chávarro)

Guabina de mis montañas que arrulla tiernos paisajes de esta tierra campesina al compás de mi canción. Yo te canto con el corazón, siento desde adentro tu fulgor, suspiros de amor hay entre tú y yo, aire de mi ser. ("Señora Guabina" - Carlos Alberto Ordoñez Rivera)

Suelten el toro, viva la reina, calmen la brasa que ya el asado se está quemando. Venga la bailo, opita linda, toma los bordes de sus encajes sus manos finas. ("Viaje a Neiva" Luciano Díaz)

\section{Lo económico y la naturaleza}

Las tensiones entre naturalezacultura, que constituyen "lo ambiental", emergen desde el llamado desarrollo y la racionalidad,

cuya imposición rompe en mil pedazos la vida en una guerra no nombrada como guerra, para los fines de una producción interminable, un consumo bulímico, una acumulación sin límites, un crecimiento monstruoso y un desperdicio de la vida, objetivada por la ciencia moderna y manipulada por la tecnología: la tierra mercantilizada y la naturaleza esclavizada se convierten en riqueza para conseguir el desarrollo. No sólo el hombre sino todo ser viviente es reducido a fuerza de trabajo en una explotación belicosa y permanente de la tierra y de todo lo que en ella habita. (Noguera y Pineda, 2017, pág. 142)

Así se ha forjado la relación entre cultura y naturaleza, como una separación, porque hemos creído estar por fuera de los ecosistemas, convirtiéndolos en "proveedores de recursos" para el anhelado "desarrollo sostenible" de una civilización que dice llamarse "moderna" por enfocarse en un crecimiento económico continuo e ilimitado que ha franqueado una guerra abierta 
contra la naturaleza. Así se canta esta crisis desde la música huilense:

es el llanto de un niño, el clamor de una madre, es plegaria de un árbol, el gemir de los ríos, es cantar de las aves, el susurro del viento, el pregón de los mares, la voz de esta canción, gritándonos que no. No, no, no, no, no, no a la guerra no. No, no, no, más violencia no. ("No, no, no" Jaime Ricardo Guío Ordóñez)

El grito cantado a unísono es: No más violencia contra nosotros mismos ni contra la naturaleza. La cultura expone en sus prácticas los mundos simbólicos que la constituyen. Así queda evidenciada la deforestación y los incendios:

El Macizo Colombiano o Nudo de Almaguer, es tu macizo hermano conócelo y protégele. Tres millones de hectáreas, majestuoso ecosistema donde lloran los páramos por la tala y las quemas. Volcanes, nevado y fauna, reserva de la biosfera nace el Patía el Cauca, Caquetá y el Magdalena. ("Suite al Macizo Colombiano" - Adolfo Hueje)

El mayor logro de la civilización moderna es el progreso, un anhelo equívoco que se hace vida en las canciones de esta manera:
Es muy cierto que el progreso es de una gran necesidad, pero hay valores eternos que debemos respetarlos con el evolucionar porque son alma del pueblo que a pesar de estar sufriendo nos dan vida en su cantar. ("Cuando retumban las tamboras" - José Miller Trujillo)

Progreso concebido como necesidad para dar forma a la sociedad moderna. Progreso negociado que se sustenta en el desarrollo por ser

autogénesis y autorrealización de la razón, se constituye, se conforma, se estructura y se desplaza de la misma manera que la razón moderna. Es la encarnación del proyecto de Modernidad. Con su luz enceguece toda otra manera de habitar esta tierra. Es totalitario, homogeneizante y unificador. Sus imaginarios están tan encarnados en la cotidianidad de nuestra cultura que lo otro, otras maneras de pensar y de obrar por fuera del Desarrollo, se considera imposible. (Noguera, 2016, pág. 90)

Progreso que el campesino busca, porque el mundo simbólico que lo constituye le dice que ser próspero es tener ganado, tierra, herramientas tecnológicas, vestido, casa y cosas. Así se alcanza la felicidad.

Y en ese sueño sintióse dueño y señor de su vida, patrón de su 
propia hacienda y de su ganadería. ("El sueño" - Guillermo Calderón Perdomo)

Vio una casita blanca, un arrozal, la molienda. Vio a su patrón sirviendo de peón en la siembra. Los hijos en la escuela, buen tractor, buena prenda y un montonón de cosas pa' su amor. ("El sueño" -Guillermo Calderón Perdomo)

Te puedo dar felicidad, aunque pobre soy, cual San Martín, compraré pa'ti, casita, chiros y platanal. ("Retazos" - Jairo Beltrán)

Un progreso que convierte los frutos del campo en productos y al ser humano en un comerciante que se explota así mismo:

Oh, mi País... pero algo en ti más fuerte ha de crecer para tu suerte; es el cantar de la raza del café, es el petróleo que hierve entre tus venas; es tu gente que no quiere más morir, es un clamor, un grito, es Colombia entera. ("Mi país" Guillermo Calderón Perdomo)

Progreso que en las ciudades muestra sus expresiones en forma de comercio libre, dejando invisibilizados los problemas que surgen:

Hay tiendas elegantes, grandes puentes importantes, máquinas que trabajan mientras hombres mueren de hambre. Hay lujuria y riqueza, niños pobres $y$ violencia, y muchos campesinos que viven en la miseria. ("Las ciudades"-Guillermo Calderón Perdomo)

Cuantos países quisieran tener lo que Dios nos dio, tierras, montañas y llanos, ríos, mares, frío y calor, el mejor café del mundo y carbón al por mayor, una patria soberana que nos dio el Libertador. (“A Colombia con amor” - Álvaro Córdoba Farfán)

Las entrañas de tu suelo tienen tesoro escondido y es el color amarillo la nobleza de tus hijos. ("Mi Huila tierra querida" Vicente Romero)

Cuando se hace sísmica se realizan explosiones capas de tierra sacude produciendo remociones, luego se hacen carreteras para torres instalar, meten tubos de presión y el crudo empieza a brotar. Que colmo resulta ahora que unas multinacionales con licencias ambientales quieren mi cuenca acabar. ("Las Ceibas no se explota" -Adolfo Hueje)

Que la cosecha ya está vendida, se ven las torres de petroleras, las veo altivas, también esquivas, me llegan aires del Magdalena. ("Viaje a Neiva" Luciano Díaz Vargas)

Vivo en un país lleno de vida, donde cada niño es ilusión, donde el campesino es de la 
tierra, donde la violencia es lo peor. ("Vivo en un país" - Víctor Hugo Reina Rivera)

Petróleo, carbón y oro mueven la economía mundial y acaban con los ecosistemas. Violencia, miseria, hambre, libertad regulada, atentan contra la vida.

Ya se asoma el alba con gran ilusión recogemos los frutos que dio la tierra, pero esto no alcanza pa' comprarle alpargatas a mis guambicitos y a mi morena, ahora bien amigo comprender mi angustia y $\mathrm{mi}$ penar, vete y no regreses ya no quiero que tú me veas llorar. ("Viento fiel amigo" - Rosalba Montilla Charry)

La soledad de su ausencia con dolor y sentimiento nos lo reclama esta tierra que los quiere de regreso, no quiere ver a sus hijos agrandando las ciudades sin fe ni oportunidades por calles en el olvido, mientras los surcos del campo reclaman al campesino a cosechar bien la tierra, eso es lo que Juan quisiera. ("Rumbos" Luís Enrique "Quike" Perdomo M.)

Miseria vas y vienes como el aire, angustia y privación como alimento. Mientras unos se divierten a otros se les muere el alma. ("Muerte y privación" Pedro J. Chávarro)
En contraste, el progreso o desarrollo, cosecha angustia, soledad, ausencia, miseria, muerte. Minería que acaba con las comunidades indígenas provocando su desplazamiento:

Papayacas Anaconas y Paeces por doquiera, las tierras les arrebatan la explotación minera, indios en sus resguardos como colchas de retazos, en ranchos atrincherados con fusil amenazados. ("Suite al Macizo Colombiano” - Adolfo Hueje)

Progreso con forma de basura, contaminación, incendios:

Están tristes los nevados, los polos están llorando, el corazón de la tierra de dolor está temblando. Tal vez la naturaleza, de algo nos quiere hablar, tal vez nos está diciendo, que ya es hora de cambiar...que no le arrojen basuras, mejor sería reciclar, que vuelva limpia los ríos, el agua para tomar, no hay que prenderle candela al bosque es la solución, para dejarle a los niños un mundo mejor que el de hoy...debemos tomar conciencia el cambio está en nuestras manos, cero contaminación. ("En mis manos" - Ricardo Castro Silva)

Metaforización de la Madre Tierra que habla así: 
Yo soy la Madre Tierra, y al hombre hay que preguntarle: ¿por qué me quemas tanto si yo te doy tus altares. Sobre mi cuerpo duermes, sobre $\mathrm{mi}$ cuerpo descansas y si tú me destruyes, dónde siembras tus labranzas? ("La Madre tierra" José Emilio Sunce)

Dónde están esos frutos que alimentaban las aves, ya no cantan las mirlas ni se escucha el muchilero, les quemaron sus nidos, les quemaron sus polluelos, las aguas se han secado, los peces también murieron. ("La Madre tierra" José Emilio Sunce)

Los ríos lloran, lloran, todos se sienten perdidos porque sus habitantes están desaparecidos, sus aguas contaminadas no las quiere el cocodrilo, el Mohán, el Poira, el Duende también están afligidos. ("La Madre Tierra" José Emilio Sunce)

\section{Conclusión}

David Wallace-Wells (2019) en su libro "El Planeta inhóspito", plantea doce "elementos del caos": muerte por calor, hambruna, ahogamiento, incendio, desastres ya no naturales, falta de agua, océanos moribundos, aire irrespirable, plagas del calentamiento, colapso económico, conflicto climático. Así, expone las problemáticas que, desde ya y cada vez peor, estamos enfrentando los humanos como consecuencia de nuestras acciones cotidianas.

En un aparte, el autor menciona: "Cada uno de nosotros impone algo de sufrimiento sobre nuestros yos futuros, cada vez que pulsamos un interruptor de luz, compramos un billete de avión o nos abstenemos en unas elecciones" (Wallace-Wells, 2019, pág. 43). Sin duda, toda acción presente repercutirá en el futuro de manera multiplicada.

La pregunta que surge es ¿cómo ha sido posible llegar a estas consecuencias tan catastróficas que amenazan nuestra propia vida?

La respuesta la encontramos en los escritos elaborados por ÁngelMaya, que revolucionó la manera de interpretar la crisis ambiental, al manifestar que se trata de una crisis de los símbolos, poniendo en el centro del problema al ser humano, o sea, la cultura.

Si somos el eje de los problemas ambientales, podemos comprendernos en medio de esta crisis a partir del estudio de los mundos simbólicos que construimos colectivamente. Para alcanzar esto, debemos tener presente que nuestra vida, es lo que es por su condición sensible la misma que define las maneras, formas y modos que tejen las tensiones entre cultura y naturaleza. 
Varios de los "elementos del caos" que alude Wallace-Wells quedan expuestos en las letras de las canciones huilenses de manera explícita o tácita. El mundo simbólico encontrado en la música huilense teje la relación culturanaturaleza desde el reconocimiento, admiración y necesidad de los ecosistemas, la analogía con lo femenino, el fulgor de las fiestas y la relación con la economía. Así se comprende lo mencionado por Frith (1987): "la cuestión que debemos responder no es qué revela la música... sobre los individuos sino como esta música los construye".

Toda esta "naturaleza transformada" de la que habla Ángel-Maya (2013) evidencia que desde la racionalidad se ha construido un ideal de desarrollo basado en la lógica capitalista, que ha enceguecido la especie humana a creer en un crecimiento ilimitado en respuesta a una historia-relato de prosperidad económica aceptada y compartida. A partir de esta se han construido los mundos simbólicos desde donde emerge la crisis ambiental, es decir, la crisis de la relación cultura-naturaleza.

El río es vida porque mantiene la labranza, y si hay alimentos, la tierra es querida. El territorio enmarcado en colores azules, verdes y amarillos, habla de los paisajes queridos, añorados. La creencia en una creación divina ha modelado la idea de ser el pueblo elegido que todos proclaman. Los mitos, que son historias como todas las otras encontradas, hablan de relatos construidos para la protección de la naturaleza. Triste o alegre la naturaleza depara los contrastes entre ausencias y nostalgias, jolgorios y alegrías.

Una "hominización de la naturaleza" (Ángel-Maya, 2013) se evidencia en licor (aguardiente, chicha, guarapo); platos típicos (tamal, lechona, envueltos, insulsos, mote, asado); instrumentos musicales (tambora); que son expresión de una vida sensible que decide "lo ambiental".

Mundos simbólicos que representan intereses económicos al hacer ganadería o cultivo industrial talando los bosques. Cantando a los "recursos naturales" que sostienen dicho crecimiento ilimitado como el petróleo, carbón y oro se impulsan el desarrollo tecnológico, las industrias y los mercados globalizantes que aniquilan cada día más ecosistemas. Cada vez que asistimos a fiestas, eventos artísticos, reuniones sociales o familiares donde cantamos las músicas que replican la crisis, vamos intensificando las problemáticas que se requieren cambiar.

¿Cuánto estamos dispuestos a transformar los símbolos que constituyen nuestra cultura? 
No queremos padecer "los elementos del caos" que anota David Wallace-Wells, nos aterra morir de calor, incinerados, ahogados, asfixiados, de hambre, de algún virus o en medio de la guerra por el agua. Sin embargo, seguimos adquiriendo los productos comerciales provenientes de las industrias que contaminan y no cumplen con lo que menciona Ángel-Maya (2013) en su libro "El reto de la vida" respecto a la transformación de la naturaleza:

El problema ambiental no consiste en conservar el orden ecosistémico, sino en saberlo transformar bien. El orden humano también es un orden natural. Ha surgido de la evolución y tiene raíces biológicas. Pertenece a la naturaleza, pero está sostenido en una estructura distinta de comportamiento que es necesario entender, para comprender debidamente la crisis ambiental. (pág. 83)

¿Estamos dispuestos a revisar qué mundos simbólicos provocan este caos? Para alcanzar la transformación simbólica es prioritario comprender que "el proceso de construcción de significado se relaciona con la necesidad de interpretar la realidad" (Hernández 2000, citado por MEN, 2010, pág. 44). Por lo tanto, la intención de cambio debe enfocarse en la construcción de resignificaciones de las metáforas que originan las tensiones entre cultura-naturaleza. En el Documento 16, “Orientaciones pedagógicas para la Educación Artística" (2010), se menciona:

En el campo de la Educación Artística, por transformación simbólica se entiende un proceso comunicativo de manipulación y modificación de los distintos lenguajes artísticos y símbolos propios de una cultura, por medio del cual el estudiante puede aprender a enriquecer sus posibilidades de expresión. La transformación simbólica recae sobre un producto específico que puede ser de carácter teatral, musical, visual, etc. Esta acción implica una especie de traducción, esto es, supone captar la esencia de una realidad, de un hecho perceptivo $\mathrm{u}$ otra expresión simbólica, para trasladarlo a otro contexto o lenguaje diferente. Dicho en otros términos, el estudiante traslada una forma, creación o situación que proviene del contexto y la convierte en su propia expresión. (MEN, pág. 44)

Transformación simbólica que desde la música se puede implementar al resignificar los mundos simbólicos que sustentan la cultura-naturaleza huilense.

El comercio de lo sensible, o sea, el intercambio simbólico que realizamos a diario desde las imágenes, define imprescindiblemente "lo ambiental" porque es la 
manera como se teje dicha relación. Creyendo que las problemáticas las originan los demás y no reconociendo en cada uno de nosotros la parte que nos corresponde, hemos presumido que la solución la encontramos por fuera de nosotros, porque la naturaleza se ha concebido como recurso:

como objeto o como sistema, decía en 1997 el filósofo Daniel Vidart. El ambiente era entonces "el entorno sistémico", en el mejor de los casos; aquello que rodea al ser humano, que está "por fuera" del sujeto, la naturaleza encomendada al hombre. Este debía entonces conservarla, cuidarla, "explotarla" adecuadamente, de tal manera que las generaciones futuras tuvieran la misma “calidad de vida" que las generaciones presentes, valga la aclaración, de humanos. (Noguera, 2016, pág. 70).

Desde nuestra vida sensible, las culturas se han relacionado con los ecosistemas, desde nuestros mundos simbólicos hemos construido naturaleza transformada.

Desde la música exponemos el mundo simbólico que evidencia la crisis ambiental que nos pone en jaque. Es hora de componer música que nos ayude a comprender y resignificar la relación entre cultura-naturaleza, y a construir "lo ambiental".

\section{Referencias}

Porque alude a la vida individual y colectiva que construimos (Chacón).

Ángel-Maya, A. (2013) El Reto de la Vida. Ecosistema y cultura, una introducción al estudio del medio ambiente. Segunda edición. Recuperado de https://www.rds.org.co/es/recu rsos/el-reto-de-la-vidaecosistemas-y-cultura-unaintroduccion-al-estudio-delmedio-ambiente

Coccia, E. (2011). La Vida Sensible. Grupal Logistical y Distribución.

Frith, S. (1987). Hacia una estética de la música popular. Recuperado de https://sociologiacultura.pbwor ks.com/f/Frith.pdf

MEN (2010). Documento No.16 Orientaciones pedagógicas para la Educación Artística en básica y media. Bogotá (Colombia). Recuperado de https://www.mineducacion.gov. co/1759/articles241907_archivo_pdf_orientacio nes_artes.pdf

Noguera, A. P. (2004). El Reencantamiento del Mundo. Universidad Nacional de Colombia. Sede Manizales.

Noguera, A. P. (2016). Voces del pensamiento ambiental. Tensiones críticas entre 
desarrollo y Abya Yala. Universidad Nacional de Colombia sede Manizales.

Noguera, A.P. y Pineda, J. (2017). Trazos en bucle para descolonizar el pensamiento ambiental en clave sur. En Reyes, F. (2017). Construir un NosOtros con la tierra. Voces latinoamericanas por la descolonización del pensamiento y la acción ambientales. Universidad de Ciencias y Artes de Chiapas. Universidad de Guadalajara. Editorial Ítaca. México.

Wallace-Wells, D. (2019). El Planeta Inhóspito. La vida después del calentamiento. Editorial Debate. Colombia.

\section{Webgrafía autores}

Otero, J. (2018). Video: Psicología, religión y mitos. PsicoCymática. Argentina. Recuperado de https://www.youtube.com/watc $\mathrm{h} ? \mathrm{v}=19 \mathrm{fAkRxcYO} 8$

\section{Webgrafía canciones}

"A orillas del Magdalena" Ricardo Castro Silva

"Suite al Macizo Colombiano" Adolfo Hueje

“A Colombia con amor" - Álvaro Córdoba Farfán). https://www.youtube.com/watc $\mathrm{h} ? \mathrm{v}=\mathrm{yC} 41 \mathrm{tOwo} 7 \mathrm{wk}$
“Al sur" - Jorge Villamil Cordovez https://www.youtube.com/watc $\mathrm{h}$ ?v=fIy6Mv6Es30

"Alma del Huila" - Luís Alberto Osorio S. https://www.youtube.com/watc $\mathrm{h} ? \mathrm{v}=\mathrm{jx} 8 \mathrm{~V} 97 \mathrm{dQhA0}$

"Caminando por el Huila"-José Ignacio Olave https://www.youtube.com/watch

"Camino real" - José Ignacio "Papi" Tovar). https://www.youtube.com/watc $\mathrm{h} ? \mathrm{v}=\mathrm{i}_{-} \mathrm{TpJLYQ} 2 \mathrm{FU}$

“Caña No. 1" - Cantalicio Rojas https://www.youtube.com/watc $\mathrm{h} ? \mathrm{v}=\mathrm{UP9zZOi} 4 \mathrm{qeA}$

"Caracolí" -Jorge Villamil Cordovez https://www.youtube.com/watc $\mathrm{h} ? \mathrm{v}=\mathrm{xNc} 3 \mathrm{rn} 7 \mathrm{yoKE}$

"Cuando retumban las tamboras" - José Miller Trujillo https://www.youtube.com/watc $\mathrm{h}$ ?v=wa9EEUi5K_g

"Culpa divina" -Jaime Ricardo Guío Ordóñez https://www.youtube.com/watc $h ? v=$ gJgPdb--PM

"El sueño" - Guillermo Calderón Perdomo https://www.youtube.com/watc $\mathrm{h}$ ?v=TUjPK_Qiwv0

"En mis manos" - Ricardo Castro Silva 
"Espumas" - Jorge Villamil Cordovez

https://www.youtube.com/watc

$\mathrm{h} ? \mathrm{v}=\mathrm{iHRIvodQzRA}$

"Fiestas opitas" - Ramiro Chávarro https://www.youtube.com/watc $\mathrm{h} ? \mathrm{v}=44 \mathrm{uzGwdDiXk}$

"Flor del campo" - Luís Alberto Osorio https://www.youtube.ce

"Guabina Huilense" -Carlos Enrique Cortés https://www.youtube.com/watc $\mathrm{h} ? \mathrm{v}=$ Q6bI_TDd-4I

"La Llamarada" - Jorge Villamil Cordovez

https://www.youtube.com/watc $\mathrm{h} ? \mathrm{v}=\mathrm{tNmoUMxNwhk}$

"La Madre tierra" - José Emilio Sunce

"Las Ceibas no se explota" -Adolfo Hueje

"Las ciudades" -Guillermo Calderón Perdomo https://www.youtube.com/watc $\mathrm{h} ? \mathrm{v}=\mathrm{SzHnIFT} 2 \mathrm{GpE}$

"Los Guaduales" - Jorge Villamil Cordovez https://www.youtube.com/watc $\mathrm{h} ? \mathrm{v}=\mathrm{zG} 63 \mathrm{zaAyPXQ}$

"Me llevarás en ti" -Jorge Villamil Cordovez https://www.youtube.com/watc $\mathrm{h}$ ?v=VRSrWoQ1Hp0
"Mensajero de paz" - Juan Pablo Rodríguez Mendoza

"Mi Huila tierra querida" - Vicente Romero https://www.youtube.com/watc $\mathrm{h} ? \mathrm{v}=\mathrm{v}-\mathrm{bNJ}-5 \mathrm{Qt} 9 \mathrm{~A}$

"Mi Huila" - Héctor Álvarez https://www.youtube.com/watc

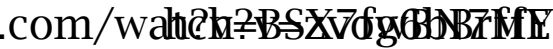

\section{"Mi país" - Guillermo Calderón Perdomo \\ https://www.youtube.com/watc $\mathrm{h}$ ?v=PqEXItZpv_s}

"Mitología Huilense" -Luis Carlos "Pipa" Prada https://www.youtube.com/watc $\mathrm{h} ? \mathrm{v}=\mathrm{rlH}-\mathrm{lWNXKHM}$

"Muchachita campesina" Gerardo Betancourt y Ruth Rojas de Polanco https://www.youtube.com/watc $\mathrm{h} ? \mathrm{v}=\mathrm{MI}-\mathrm{y} \_w V o g N E$

"Muerte y privación" Pedro J. Chávarro https://www.youtube.com/watc $\mathrm{h} ? \mathrm{v}=\mathrm{hO64fP5ajN} 4$

“No, no, no” - Jaime Ricardo Guío Ordóñez https://www.youtube.com/watc $\mathrm{h}$ ? $=\mathrm{k} 6 \mathrm{rpesa22qg}$

"Retazos" - Jairo Beltrán https://www.youtube.com/watc $\mathrm{h} ? \mathrm{v}=8-\mathrm{y} 9 \mathrm{SezPhLM}$

"Rumba Opita" - Luis Alfonso Castellanos 
https://www.youtube.com/watc $\mathrm{h} ? \mathrm{v}=\mathrm{GJqkC} 4 \mathrm{TUQgI}$

"Rumbos” - Luís Enrique "Quike” Perdomo M.

"Sanjuanero huilense" - Anselmo Durán Plazas https://www.youtube.com/watc $\mathrm{h} ? \mathrm{v}=\mathrm{IebhsKmHcvo}$

"Señora Guabina” Carlos Alberto Ordoñez Rivera
"Suite al Macizo Colombiano" Adolfo Hueje

"Viaje a Neiva" - Luciano Díaz https://www.youtube.com/watc $\mathrm{h} ? \mathrm{v}=\mathrm{Yz} \mathrm{z}_{-}-\mathrm{nPkImxs}$

"Viento fiel amigo" - Rosalba Montilla Charry

"Vivo en un país" - Víctor Hugo Reina Rivera https://www.youtube.com/watc $\mathrm{h}$ ?v=Je8y6VWr5dw 